\title{
CONTRIBUIÇÕES PARA UMA VISÃO BASEADA EM RECURSOS LEGIITIMOS
}

CONTRIBUTIONS TO A LEGITIMATE RESOURCE-BASED VIEW

\section{RESUMO}

Neste artigo teórico, discutimos as noções de recursos da firma e de legitimidade para explicação da eficiência estratégica de organizações. Como contribuição principal, propomos, a partir da tendência atual da Visão Baseada em Recursos (VBR) e da Nova Teoria Institucional (NTI), uma perspectiva alternativa, denominada Visão Baseada em Recursos Legítimos, relacional e intepretativa, que permita entender a intersubjetividade e a dinamicidade presentes no processo de elaboração da estratégia em organizações.

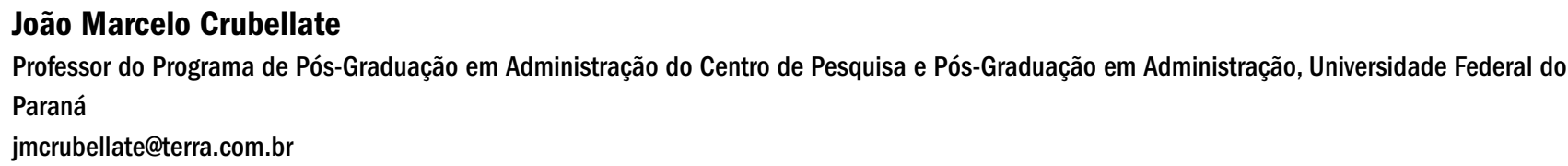

\section{Lucilaine Pascucci}

Doutoranda no Programa de Pós-Graduação em Administração, Pontifícia Universidade Católica do Paraná lucilainep@yahoo.com.br

\section{Paulo Sérgio Grave}

Professor aposentado do Departamento de Administração, Universidade Estadual de Maringá pgrave@uol.com.br

Recebido em 15.08.2005. Aprovado em 25.06.2008

Avaliado pelo sistema double blind review

Editor Científico: Luiz Artur Ledur Brito

ABSTRACT In this theoretical article we discuss the notions of company resources and legitimacy to explain the strategic efficiency of organizations. As its main contribution, starting from the current trend towards a resource-based view (RBV) and the new institutional theory (NIT), we propose an alternative relational and interpretative perspective, called a legitimate resource-based view, which allows for an understanding of the inter-subjectivity and dynamics present in the strategy preparation process in organizations.

PALAVRAS-CHAVE Legitimidade, recursos, estratégia, VBR, interpretação.

KEYWORDS Legitimacy, resources, strategy, VBR, interpretation. 


\section{CONSIDERAÇÕES INICIAIS}

O presente trabalho propõe uma abordagem teórica alternativa, ancorada na Visão Baseada em Recursos (VBR) e na Nova Teoria Institucional (NTI), que chamaremos aqui Visão Baseada em Recursos Legítimos. Essa abordagem caracteriza-se por rediscutir as noções de recursos, legitimidade e racionalidade à luz da perspectiva relacional e interpretativa proveniente da perspectiva analítica oferecida pela NTI para entendimento da interação entre organizações e ambiente organizacional.

A VBR é uma perspectiva explicativa do comportamento estratégico, fundamentada na idéia de que seleção, obtenção e disposição de recursos e desenvolvimento de competências únicas ou de difícil imitação resultam em diferenciação e vantagem competitiva sobre concorrentes. Apesar de o foco analítico ser interno às organizações, a noção de ambiente é igualmente importante no âmbito da VBR. Em algumas das teorias baseadas em recurso, admite-se que o valor de recursos e capacidades depende de condições externas às firmas (BARNEY, 2001b; FOSS e FOSS, 2005).

Ao agregar a variável ambiental, do modo como isso é feito na VBR, os teóricos da NTI se filiam ao amplo conjunto de teorias pautadas no pressuposto de limites da racionalidade para explicar decisões de atores sociais e organizações (BARNEY, 2001b). Em função de sua vinculação com a economia, entretanto, autores vinculados à VBR enfatizam geralmente limites de ordem concreta, objetivamente acessíveis - excetuadno-se Helfat e Peteraf (2003). Como destaca Barney (2001b), a existência de limites objetivos à racionalidade é pressuposto comum às teorias microeconômicas neoclássicas, tanto quanto a variação na competitividade dos mercados, a variação nos modos de difusão de informação naqueles mercados, e assim por diante.

Contudo, esses limites não são todas as restrições que se impõem ao decisor. Algumas teorias organizacionais, dentre elas a Nova Teoria Institucional (NTI), enfatizam aspectos culturais para sugerir que a própria interpretação da realidade, fruto da interação entre pessoas, interpõe-se entre decisor, pressões ou oportunidades ambientais e a organização. A principal consequência dessa constatação é que precisamos entender o processo de interpretação tanto quanto, ou até mais do que, os limites concretos presentes no entorno organizacional -, se quisermos entender como os recursos e contexto afetam as decisões.

A perspectiva institucional vem sendo crescentemente utilizada para explorar a natureza socialmente construída da estratégia (WHITTINGTON, 1992; QUEIROZ,
VASCONCELOS e GOLDSZMIDT, 2007). Uma de suas premissas centrais afirma que o tipo de ordem - arranjo social - produzida pelas instituições influencia o processo de competição com base na utilização de recursos e, portanto, influencia resultados, como produtividade e crescimento econômico.

A partir da revisão dos pressupostos da VBR e do tratamento dispensado ao conceito de legitimidade na NTI que exploraremos mais detalhadamente na terceira etapa deste artigo -, acreditamos na possibilidade de rediscussão da noção de estratégia, via inclusão de referências institucionais não apenas enquanto limitativas, mas também enquanto habilitadoras de ações, caminhando assim para uma Visão Baseada em Recursos Legítimos.

$\mathrm{Na}$ próxima etapa deste artigo, apresentam-se as idéias centrais referentes à VBR. Em seguida, abordam-se a noção de legitimidade em NTI, com destaque para o seu caráter interpretativo, e o seu impacto na discussão acerca da ação social. Feito isso, explicitaremos, na quarta etapa, a proposta de uma Visão Baseada em Recursos Legítimos. Finaliza-se delineando a importância da proposta para a estratégia em organizações.

\section{VISÃO BASEADA EM RECURSOS: A COMBINAÇÃO "ÓTIMA" DE RECURSOS COMO FONTE DE VANTAGEM COMPETITIVA}

Desde Penrose (1959), a abordagem dos recursos da firma está presente na análise dos fatores explicativos do crescimento das organizações; mas a abordagem ganhou ênfase a partir das análises da firma com base em seus recursos internos, ao que se denominou Visão Baseada em Recursos. No sentido mais básico, a VBR é uma perspectiva teórica em que recursos organizacionais são vistos a partir de seu sentido estratégico, como fontes de vantagens competitivas sustentáveis (WERNERFELT, 1984; BARNEY, 1991, 2001b). O modo como as firmas utilizam tais recursos faz com que elas sejam fundamentalmente heterogêneas (PETERAF, 1993; RUGMAN e VERBEKE, 2002). Essa concepção de heterogeneidade vem do pressuposto que admite a natureza da competição determinada por meio do estabelecimento de barreiras à imitação e constantes inovações. Diferentemente do que se supõe na teoria econômica neoclássica, na VBR nem todos os recursos e capacidades têm oferta elástica, até por que, para serem desenvolvidos, alguns deles necessitam de longo período de tempo. Essa inelasticidade de oferta implica que firmas possuidoras de recursos valiosos podem obter vantagem competitiva sustentável (PETERAF, 1993; 
BARNEY, 2001b). Por isso, são questões fundamentais na formulação da estratégia da firma, a partir da VBR: "quais" recursos são selecionados, "como" são selecionados e utilizados.

As perspectivas da organização industrial e de mercado para entendimento do posicionamento estratégico focalizam condições externas à firma. A VBR, ao contrário, lança seu foco principalmente sobre suas condições internas, analisando como são obtidos, combinados e aplicados os recursos da firma, definidos como bens ou inputs tangíveis ou intangíveis que uma organização possui, controla ou a que tem acesso em base semipermanente (HELFAT e PETERAF, 2003). Outras definições e classificações de recursos propostas na literatura especializada podem ser encontradas nos textos de Barney (1997), Grant (1991) e Collis e Montgomery (1995). Seleção, acumulação e aplicação de recursos são entendidas como funções da tomada de decisão no âmbito interno da organização, não se negando a importância de fatores do contexto externo. Tais fatores, porém, são entendidos como passíveis de análise e decisão estratégica, isto é, como objetivos e sujeitos, ainda que limitadamente, a escolha racional. Ambiente, assim, constitui um conjunto de condições concretas e externas a serem consideradas no planejamento das ações organizacionais, sendo tais ações produto de atores sociais em busca da combinação e utilização "ótimas" de recursos - tomados como tendo natureza predominantemente geral e externa, portanto objetiva, às organizações -, limitados por várias condições. Tal premissa coincide com axiomas fundamentais da teoria da escolha racional; principalmente com: o individualismo ou reducionismo metodológico, em que os fenômenos sociais são explicados por decisões e ações individuais; o conseqüencialismo ou utilitarismo, em que os agentes consideram as conseqüências de suas ações e, portanto, têm consciência delas; e a maximização, em que os agentes escolhem ações cuja relação custo-benefício lhes é mais favorável (BOUDON, 2003). Mesmo quando se admitem limites nessa racionalidade instrumental ou estratégica, tais axiomas não são alterados, permanecendo como princípios da ação nas teorias de economia das organizações. Convém destacar que Boudon (2003) define como racionalidade instrumental a noção presente na Teoria da Escolha Racional. Chamamos a mesma lógica de estratégica, por vezes neste artigo, para destacar o lado consciente e intencional dessa instrumentalidade.

Em continuidade, na VBR, a firma tende a ser definida como "pacote" de recursos únicos (SPANOS e LIOUKAS, 2001), devido às opções disponíveis sobre as quais constituirá sua área de competência (FOSS, 1997). Destaca-se, portanto, a utilização de recursos, partindo do princípio de que organizações são fundamentalmente heterogêneas, posto que dispõem de recursos diferentes (PETERAF, 1993; RUGMAN e VERBEKE, 2002). De acordo com Spanos e Lioukas (2001), essa heterogeneidade origina-se de diferentes recursos e capacidades nos quais as firmas baseiam suas estratégias, ou, ainda, do fato de que nem todos os recursos são perfeitamente móveis e elásticos. Mobilidade e elasticidade parciais resultam da existência de recursos mais e menos valiosos e, portanto, oferecem maior ou menor vantagem competitiva, de acordo com os recursos que as organizações possuem. Para alguns autores, essa condição de heterogeneidade é construída no âmbito organizacional interno e mediante combinação de recursos, aproveitando-se as rotinas organizacionais e sistemas coletivos de aprendizado, criando-se capacidades que são valiosas justamente por sua natureza endógena e porque não podem ser compradas. Nessa perspectiva, o que torna um recurso valioso é a forma peculiar como é utilizado pela firma (TEECE e PISANO, 1994). Outros autores expandem a noção de recursos, admitindo que seu valor, pelo menos em parte, depende de condições provenientes do ambiente (BARNEY, 2001a; FOSS e FOSS, 2005).

Essa evolução conceitual dos recursos, na VBR evidencia a crescente importância de aspectos vinculados à legitimidade da firma, quando se nota a inclusão de reputação, além de outros aspectos atrelados ao ambiente social com que lidam as organizações: conhecimento, capacidade inovadora, ciência e tecnologia, política governamental. Deve-se destacar também que tais elementos ainda são entendidos, na literatura especializada, como fatores ambientais objetivos a serem adquiridos ou desenvolvidos pela organização e estrategicamente utilizados para obtenção de vantagem competitiva.

Esse objetivismo da VBR é percebido mesmo em textos em que se defende que as capacidades da firma, em ambiente competitivo, precisam ser dinâmicas a fim de responderem apropriadamente ao contexto em transformação (TEECE e PISANO, 1994). Esses mesmos autores enfatizam o papel-chave da administração estratégica em manter as qualificações organizacionais, competências funcionais e recursos integrados e atualizados em face desse contexto. Observe-se a nítida dicotomia entre organizações e ambientes, distintos de forma aguda por fronteiras organizacionais objetivamente delineáveis. Supõe-se igualmente como papel do gestor o monitoramento das condições ambientais e a adequação estratégica das capacidades organizacionais para acompanhar as alterações do ambiente. Tal objetivismo trai a própria noção de recursos 
na VBR, ao menos nas teorias de recursos que incluem o ambiente como fonte do valor dos próprios recursos, conforme discute Barney (2001b) a respeito da dependência de caminho (path-dependence) como condição de desenvolvimento de certos recursos e capacidades. Nesse sentido, De Gregori (1987) define como proveniente da Economia Clássica a noção de recursos materiais, naturais ou objetivamente "dados". A partir da teoria institucional, ele defende uma perspectiva de entendimento na qual "[...] recursos essencialmente não têm significado à parte do relacionamento entre seres humanos [...]" (De GREGORI, 1987, p. 1242). As implicações dessa proposição para a análise em estratégia não foram ainda delineadas. Principalmente, ela sugere outra definição de recursos, próxima à noção defendida por Giddens (2003), para quem não são bens ou inputs em si que geram potencial de controle sobre outros objetos e bens e sobre pessoas ou atores sociais. Tal potencial provém da capacidade transformadora daqueles recursos, sendo que essa capacidade depende do seu significado e, conseqüentemente, de sua legitimidade social. Esse é o sentido de recursos, neste artigo, quando discutidos no âmbito das condições para uma Visão Baseada em Recursos Legítimos.

A noção de recursos ainda vinculada à herança clássica reflete o que sugerem Acedo, Barroso e Galan (2006), para quem a VBR constitui-se em corpo teórico relativamente diverso que comporta tendências parcialmente distintas entre si. Eles afirmam que a parte mais tradicionalmente vinculada à VBR (os artigos que originaram a perspectiva) vem sendo criticada pelo caráter estático da teoria que propõe. Já textos mais recentes admitem perspectiva dinâmica e até uma visão construtivista dos recursos, tanto quanto começam a romper com a distinção radical entre organização e seu meio. Um dos melhores exemplos disso é o texto de Foss e Foss (2005), em que recursos são discutidos a partir da noção de direito de propriedade, agregando-se explicitamente a influência do meio social como fonte de valor dos recursos, não apenas de modo restritivo. Para os autores, a condição trazida pelas características do meio social é também fonte do próprio valor do recurso, sendo que "o modo como direitos de propriedade são restringidos por lei, acordos ou normas influencia quanto valor um proprietário de qualquer recurso pode criar e apropriar daquele recurso" (FOSS e FOSS, 2005, p. 543). É esse sentido constitutivo do meio social, em relação aos recursos, que agregam algum grau de dinamicidade e intersubjetividade à VBR, que pretendemos explorar neste artigo. Acreditamos, com isso, que valiosa contribuição pode ser extraída da NTI.
Parte importante da literatura sobre estratégia baseada na noção de recursos não discute a fonte do valor dos recursos que se admite como sendo a base para a vantagem competitiva de firmas. A condição de sustentação da vantagem competitiva é um dos pontos focais da VBR, mas até recentemente ela era explicada principalmente pelo grau de eficiência resultante da utilização de sua dotação de recursos, ou a "[...] posse de recurso valioso que capacita a companhia a desempenhar suas atividades de forma mais eficiente e barata do que seus competidores" (COLLIS e MONTGOMERY, 1995, p. 120). Igualmente em Peteraf (1993), as condições-chave para sustentação da vantagem competitiva - heterogeneidade, limites de competição ex ante, limites para competição ex post e mobilidade imperfeita - são tratadas como existindo por si e de modo estático no contexto organizacional. Falta discutir o seu caráter dinâmico, a sua origem, o que parece ser uma exigência e uma tendência da VBR (HELFAT e PETERAF, 2003). Nisso, ela segue tendência proveniente de recentes abordagens à decisão em organizações sob perspectiva que considera, ao lado dos limites objetivos à racionalidade do decisor (ou seja, aqueles aspectos que impedem que uma ação não satisfaça plenamente as condições de utilidade e maximização, a despeito da intenção do ator), as condições culturais e interpretativas que se estabelecem no contexto da decisão (THORNTON, 2002; WEBER e GLYNN, 2006).

No tópico seguinte, discutimos a perspectiva da NTI para a decisão estratégica. Enfocaremos a legitimidade como aspecto central para incorporar a dimensão social na discussão da racionalidade estratégica, delineando condições para uma versão ampliada da VBR, baseada em premissas institucionais, que incorpore dinamicidade à explicação da origem do valor dos recursos na produção de vantagem competitiva.

\section{INSTITUIÇÕES E LEGITIMIDADE: CONTRIBUIÇÃO DA NOVA TEORIA INSTITUCIONAL}

À semelhança da VBR, a NTI define racionalidade em organizações como possuindo limites de variada ordem. Entretanto, na teoria institucional, tais limites não apenas restringem a decisão, como também constituem a decisão, visto que restringem as opções de escolha, mas também geram estímulos e abrem vias que não existiriam ou não seriam viáveis, ou percebidas, de outra forma (THORNTON, JONES e KURY, 2005; WEBER e GLYNN, 2006).

De acordo com premissas institucionais, não decidimos sem concurso de referências sociais, sem condiciona- 
mento de normas, valores e visões de mundo socialmente predominantes. Para DiMaggio e Powell (1991, p. 28), a NTI tem como fundamento a noção de que "atores e seus interesses são institucionalmente construídos". Esse condicionamento foi por vezes entendido como determinismo social e contraposto de forma radical ao atomismo da perspectiva da escolha racional. De fato, a teoria institucional em sociologia e em teoria das organizações rejeita a premissa de que o fenômeno organizacional é produto apenas de escolha racional, visando à maximização da eficiência técnica (HALL e TAYLOR, 2003; MEYER, 2006). Como alertam Hall e Taylor (2003, p. 211), "nada nisso tudo sugere que os indivíduos não sejam dotados de intenções ou sejam irracionais. Os teóricos do institucionalismo sociológico sublinham que a ação considerada "racional' é ela própria um objeto socialmente constituído". Essa afirmação nega a idéia de fechamento lógico do tipo "atores geram instituições que geram atores" e, portanto, tudo se equilibra definitivamente. Como Hall e Taylor (2003) afirmam, instituições são apenas o produto parcial de indivíduos racionais e esses raramente agem segundo uma única referência institucional e de modo totalmente responsivo a ela. Por outro lado, instituições são fenômenos coletivos, raramente o produto da intenção de um ou poucos indivíduos. Em resumo, indivíduos sempre são, em contextos de ação, reflexivos em algum grau, nunca plenamente determinados por padrões institucionais. De igual modo, esses padrões nunca são apenas o produto da intenção desses indivíduos, tanto mais quanto mais isoladamente agirem.

Os teóricos institucionalistas demonstravam, até recentemente, mais interesse em explicar a uniformidade do que a diversidade. Isso decorre de um construto central da NTI, o isomorfismo, que captura a extensão na qual os desígnios organizacionais adotados tendem, quase sempre, a aumentar a homogeneidade das organizações ao longo do tempo. O foco no isomorfismo organizacional manteve afastadas, durante algum tempo, a teoria institucional e a área de estratégia, para a qual, tradicionalmente, a noção de escolha deliberada e consciente é cara. Enquanto o foco da teoria institucional esteve nos processos isomórficos, não se desenvolveu uma perspectiva institucional da estratégia em organizações.

As noções de recursos e ambiente institucional são discutidas por Scott (2001, p. 56), para quem "organizações requerem mais do que recursos materiais e informação técnica se elas pretendem sobreviver e prosperar em seus ambientes sociais. Elas também precisam de aceitabilidade e credibilidade social". Legitimidade, aqui, é requisito para a sobrevivência organizacional, não no sentido de somar com recursos materiais, mas no da "outra face da moeda" do próprio ambiente operacional, em que organizações competem por recursos, sob critérios de eficiência técnica.

No mesmo sentido, DiMaggio e Powell (1983, p. 148) mostram que o isomorfismo ocorre quando, "a longo prazo, agentes organizacionais, tomando decisões racionais, constroem ao seu redor um ambiente que restringe sua habilidade de continuar mudando nos anos seguintes". Dessa perspectiva, não há dicotomia entre racionalidade e forças ambientais. O processo de institucionalização decorre das decisões que, para os agentes que as tomam, são racionais. Para entender tal caráter circular entre decisões racionais e institucionalização, é preciso que se entenda a natureza do fenômeno da legitimidade e sua íntima dependência dos processos de interpretação e construção de significado, presentes na NTI. Para Suchman (1995, p. 574), "legitimidade é a percepção ou pressuposição generalizada de que as ações de uma entidade são desejáveis ou apropriadas dentro de algum sistema socialmente construído de normas, valores, crenças e definições". Esse é um sentido predominantemente, mas não exclusivamente, normativo. Ele também aponta dois sentidos em que a legitimidade vem sendo estudada nas teorias organizacionais. No âmbito de teorias como as de economia organizacional, entende-se que ela possa ser buscada e planejada intencionalmente, decorrendo de cálculo instrumental próprio das abordagens estratégicas baseadas no pressuposto da escolha racional. Essas teorias incluem até algumas vertentes institucionalistas da economia de organizações, definidas por Hall e Taylor (2003), como institucionalismo de escolha racional. Esse é também o sentido que parece predominar na VBR, até há pouco tempo, ainda que se reconheçam os limites impostos à decisão racional de acumulação e uso dos recursos. Assim, a legitimidade é tratada como outro tipo de recurso, ao lado de recursos financeiros e materiais.

Uma segunda abordagem da legitimidade, de acordo com Suchman (1995), corresponde à abordagem institucional. No âmbito da NTI, legitimidade provém de dinâmicas estruturantes dos setores sociais mais amplos e, desse modo, fora do escopo de controle proposital de qualquer ator individual, pelo menos na sua totalidade (BIDWELL, 2006; MEYER, 2006). Ela resulta de escolhas baseadas em premissas a respeito do ambiente que, então e em grande medida, é tomado como certo pela organização. Ao assumir pressupostos aceitos no ambiente, a organização atrai para si aceitabilidade e reconhecimento, isto é, legitimidade.

A distinção entre abordagens estratégica e institucional da legitimidade segue a visão dicotômica que pressupõe 
incompatibilidade entre processos de institucionalização e a capacidade de agência estratégica. Isoladamente, elas não explicam como agência estratégica e estruturas sociais se relacionam para produzir ações sociais significativas, ao mesmo tempo livres e culturalmente imersas. Em decorrência da percepção generalizada dos limites impostos por essas perspectivas, ganhou impulso na teoria social e organizacional o esforço para tentar superá-las, conforme apontam Roberts e Greenwood (1997).

Nesse sentido, a NTI vem demonstrando que mesmo respostas a contextos ambientais altamente institucionalizados pressupõem capacidade de agência (OLIVER, 1991; HALL e TAYLOR, 2003). Igualmente, estudos sobre a capacidade humana de agência indicam que nenhuma ação dispensa as condições sociais e cognitivas como orientações necessárias e o próprio fundamento da ação (GIDDENS, 2003; HALL e TAYLOR, 2003). O que esses autores defendem é uma definição de ação que compreende, ao lado da intencionalidade, também a importância de conseqüências imprevistas. Os resultados da ação nem sempre poderão ser explicados apenas pela intenção dos atores sociais. Esse argumento é importante para explicar a dualidade estrutura-ação, que implica reconhecer não se encontrarem em pólos distintos e isolados, mas serem a condição uma para a outra, de modo que "[...] propriedades estruturais de um sistema social são, ao mesmo tempo, meio e fim das práticas que elas [isto é, as propriedades estruturais] recursivamente organizam" (GIDDENS, 2003, p. 30). Enquanto traços de memória, as estruturas sociais subjazem a processos cognitivos e interpretativos, ou seja, é mediante esses processos que elas ganham vida e se tornam operantes.

De igual modo, Hall e Taylor (2003, p. 210) afirmam que "[...] para estabelecer uma linha de ação, o indivíduo utiliza os modelos institucionais disponíveis ao mesmo tempo em que os confecciona". A noção de recursividade refere-se exatamente a essa premissa de que ações tanto são fundamentadas nas estuturas sociais quanto as criam: outra vez afirmam Hall e Taylor (2003, p. 210) que "[...] instituições influenciam o comportamento ao fornecer esquemas, categorias e modelos cognitivos que são indispensáveis à ação, mesmo porque, sem eles, seria impossível interpretar o mundo e o comportamento dos outros atores".

Em decorrência disso, pode-se rediscutir a estratégia para comportar de forma recursiva referências institucionais. Superada a contradição entre agência estratégica e instituições, ambas as noções passam a ser crescentemente admitidas como complementares. Indo além, Hinings e Greenwood (1988, p. 14) afirmam que "estruturas e sistemas $[. .$.$] não são neutros, mas incorporam intenções,$ aspirações e propósitos". Dessa perspectiva, estruturas ou referências institucionais não podem ser admitidas como forças de supressão da capacidade de agência, uma vez que elas próprias incorporam as intenções que são, por sua vez, aspectos fundamentais da ação. A circularidade entre escolha estratégica e estruturas institucionais decorre do processo de interpretação que necessariamente se interpõe entre as pressões ambientais e as respostas estratégicas elaboradas no âmbito das organizações. Assim, "[...] enquanto ambientes apresentam situações e desafios reais aos gerentes dentro de uma organização, essas situações e desafios têm de ser interpretados e passar por processo de significação" (HININGS e GREENWOOD, 1988, p. 43).

Dessa forma tem-se outra visão a respeito do impacto de padrões institucionais (e da legitimidade) não como força determinista e direta sobre as escolhas organizacionais, mas como dependentes da capacidade organizacional de processar aquelas forças e interpretá-las. Para Scott (2001, p. 59), "[...] legitimidade não é commodity a ser possuída ou trocada"; ela se refere à consonância percebida com relação a regras, normas e leis relevantes, ou alinhamento com estruturas cultural-cognitivas. Dessa forma, ocorre em três dimensões: no sentido legal, "organizações legítimas são aquelas [...] operando de acordo com requerimentos legais ou quase-legais relevantes" (SCOTT, 2001, p. 60). No sentido normativo, são aquelas que internalizaram controles de natureza moral. No sentido cognitivo, organizações legítimas são aquelas que adotam "[...] estruturas ou identidades ortodoxas para se relacionar com situações específicas [...]" (SCOTT, 2001, p. 61).

Dessa forma, admitimos aqui que legitimidade não é recurso objetivo a ser obtido e utilizado estrategicamente, mas elemento constituído e constitutivo, em co-dependência com recursos e processos interpretativos. Geralmente, legitimidade tende a ser entendida como fator cuja ausência pode ser limitante para obtenção de outros recursos. Sem negar isso, sugerimos que também se pode olhar o aspecto constitutivo da legitimidade, uma vez que fatores diversos adquirem a propriedade de ser valiosos (e mesmo de poder ser definidos como recursos, no sentido da VBR mais recente) somente quando são legitimamente interpretados como sendo valiosos.

Por outro lado, a própria teoria institucional admite, em geral, que significados predominantes em uma organização têm origem no próprio contexto social. A relação entre organizações e ambientes é, na NTI, reconhecida como tendo natureza recursiva, visto que o mesmo ambiente composto por regras que afetam a organização é constituído pelos atores organizacionais, em interação 
(MACHADO-DA-SILVA e FONSECA, 1999). Esses mesmos autores resgatam a noção de estratégia dentro do escopo teórico institucional ao sugerirem que a capacidade de atender as referências institucionais resulta em maior legitimidade, o que, em decorrência, "[...] contribui para o êxito das estratégias implementadas e, por conseguinte, para o [seu] pleno funcionamento interno" (MACHADODA-SILVA e FONSECA, 1999, p. 31).

Assim, o sucesso da estratégia não depende apenas da qualidade técnica, senão também de sua legitimidade, e a própria qualidade técnica depende do atendimento de critérios de legitimidade. Por essa razão, aspectos considerados técnicos podem ser institucionalizados em grau mais elevado, visto se tornarem tão naturalizados que não são mais percebidos como constituídos na interação social (HOLM, 1995). Parece plausível admitir então que para a NTI padrões institucionais e eficiência estratégica podem ser fenômenos co-dependentes, estruturados e estruturantes entre si (HININGS e GREENWOOD, 1988). Nisso, eles são intermediados por processos de interpretação ou construção de significados que terminam por estabelecer as condições mediante as quais critérios de legitimidade definirão o que é ser eficiente; tanto quanto processos, estruturas e ações eficientes acabarão definindo quais dessas estruturas, ações e processos serão legítimos.

O entendimento de legitimidade institucional, de um lado, como recurso estratégico a ser obtido pela organização e fator limitante da capacidade das empresas para alcançar a plena racionalidade estratégica; e, de outro, como elemento estruturado e estruturante da definição da própria eficiência estratégica são duas possibilidades de conjugação da estratégia com a teoria institucional. Essas possibilidades são mais bem delineadas na parte seguinte deste artigo, aplicada especificamente à noção de recursos, nos termos tratados na VBR.

\section{APONTAMENTOS PARA UMA VISÃO BASEADA EM RECURSOS}

O que chamamos aqui de Visão Baseada em Recursos Legítimos pode ser definida como a concepção a partir da qual legitimidade é entendida como força não apenas limitativa ou restritiva, mas também constitutiva da racionalidade, dos recursos e, portanto, das ações que visam obter eficiência estratégica. Para melhor esclarecimento dessa abordagem e de sua relação com a VBR e a NTI, é necessário rever as noções de diferenciação e de homogeneização organizacionais, provenientes dessas duas perspectivas.
Como teoria explicativa, a VBR se detém sobre a heterogeneidade das organizações. Já a NTI vem sendo descrita como perspectiva especialmente útil na explicação da homogeneização organizacional, mas pobre para explicar o surgimento de diferenciações (OLIVER, 1991, 1997). Se for admitida a validade da noção de escolha racional absoluta como explicativa do comportamento de fato, tem-se então que a intenção de otimização gera diferenciação. Mas, quando se aceita que tal otimização intencional não se efetiva na realidade empírica (ou seja, quando se admite o princípio da racionalidade limitada), então é plausível admitir que alguns fatores que limitam a percepção e a ação de decisores e organizações valores, crenças, visões de mundo e especialmente a necessidade de legitimidade legal, normativa ou cognitiva - podem ter origem no contexto social coletivo. Isso significa, por sua vez, que organizações que agem sob intenção de maximização dos recursos podem, mesmo assim, seguir orientações semelhantes e, ainda que seus dirigentes pensem estar compondo conjuntos diferentes de recursos únicos ou tomando decisões inéditas de alocação, estarão sujeitos às condições do meio e do próprio processo de interpretação e poderão adotar escolhas semelhantes, passando por processos de isomorfismo enquanto acreditam estar se diferenciando. E isso não a despeito, mas por causa da otimização (DIMAGGIO e POWELL, 1983, p. 148).

Outro ponto de convergência entre VBR e NTI é apresentado por Oliver (1997), para quem acumulação e seleção de recursos dependem de decisão no âmbito interno da organização e também de fatores estratégicos externos (BARNEY, 2001a, 2001b; HELFAT e PETERAF, 2003; FOSS e FOSS, 2005). O conhecimento da situação interna dá ao gestor condições apenas parciais de decidir sobre a melhor utilização dos recursos, já que a informação disponível é limitada, no que diz respeito ao ambiente externo. Internamente, as escolhas são guiadas por intenção de racionalidade e por motivos de eficiência, efetividade e lucratividade. Já influências externas são fatores estratégicos do mercado, incluindo o poder de compradores e fornecedores, intensidade de competição e estrutura de mercado do produto.

Esses fatores, segundo Oliver (1997, p. 698), "influenciam quais recursos são selecionados e como são selecionados e alocados". Nesse contexto, decisões a respeito das alternativas que se apresentam dependem, além de outros fatores, da estratégia de crescimento, da disponibilidade e da alocação dos recursos exigidos para tal decisão e do ambiente institucional em que a organização está inserida. 
A busca pela eficiência necessária à manutenção de sua posição no mercado faz com que as organizações mantenham-se atentas à evolução do seu ambiente. Este afeta a tomada de decisão, assim como seus resultados, pois, ao mesmo tempo em que limita, também potencializa a ocorrência de mudanças. Isso ocorre porque organizações operam em ambientes que, além de competitivos, são institucionais. No mesmo sentido, o valor de mercado de cada recurso possui relação direta com o valor dele na estratégia da empresa. Assim, até mesmo a definição de recurso acaba sendo diferente para firmas diferentes, pois seu valor dependerá do que ele representa para a organização, e isso - o que ele representa - dependerá da estratégia perseguida; tal estratégia, por sua vez, dependerá das alternativas possibilitadas por normas e costumes.

Esses apontamentos indicam uma versão diferente da concepção clássica (ACEDO, BARROSO e GALAN, 2006) para o entendimento da legitimidade institucional como sendo restritiva da racionalidade. Na versão até recentemente encontrada na VBR, legitimidade institucional em qualquer de seus aspectos era no máximo entendida como outro dos limitantes da escolha racional. Esse é um sentido negativo, no qual a necessidade de cumprir requisitos legais, normativos ou cultural-cognitivos afeta o cálculo utilitário da busca por eficiência na composição do conjunto de recursos. De qualquer modo, o que ela indica é que a definição da melhor composição de recursos e competências, em termos de eficiência, depende de padrões institucionalizados. Assim os critérios institucionais de legitimidade serão entendidos como limitantes, consciente e inconscientemente, da busca pela eficiência estratégica, quando se decide a respeito da seleção, acú- mulo e disposição dos recursos organizacionais, de modo que o resultado não é a eficiência absoluta e sim a composição de recursos e competências de modo apenas limitadamente eficiente. Essa possibilidade é tentativamente representada na Figura 1

Observe-se que, apesar do acréscimo dos padrões instituticionais na explicação da vantagem competitiva, não há significativa diferença do que já se defende no âmbito das teorias baseadas em recursos. Como já ressaltamos anteriormente, vários textos recentes vêm-se desenvolvendo no sentido de incorporar o ambiente como fonte do valor dos recursos, além da própria opção estratégica da firma. Assim, o que a Figura 1 retrata é um conjunto típico de relações conceituais da VBR, como ela se apresenta hoje, inclusive no entendimento mais convencional de que as condições que se impõem sobre a racionalidade do decisor têm papel apenas limitativo daquela racionalidade.

É exatamente esse ponto que nos serve para sugerir outra via de entendimento do papel das condições institucionais como sendo também constitutivas da racionalidade e, em decorrência, dos próprios recursos da firma que são, por sua vez, fontes de vantagem competitiva. Assim, numa segunda possibilidade explicativa, a legitimidade não é tratada apenas como restritiva, mas também como habilitadora da possibilidade de otimização dos recursos. Por meio de processo circular (GIDDENS, 2003; THORNTON, JONES e KURY, 2005), baseado na noção de interpretação, eficiência e legitimidade são entendidas como fenômenos co-dependentes, socialmente construídos na medida em que agentes respondem a pressões ambientais que têm sua origem nas interações dos próprios agentes, conforme tentativamente representado a seguir.

Figura 1 - Recursos, legitimidade e eficiência limitada

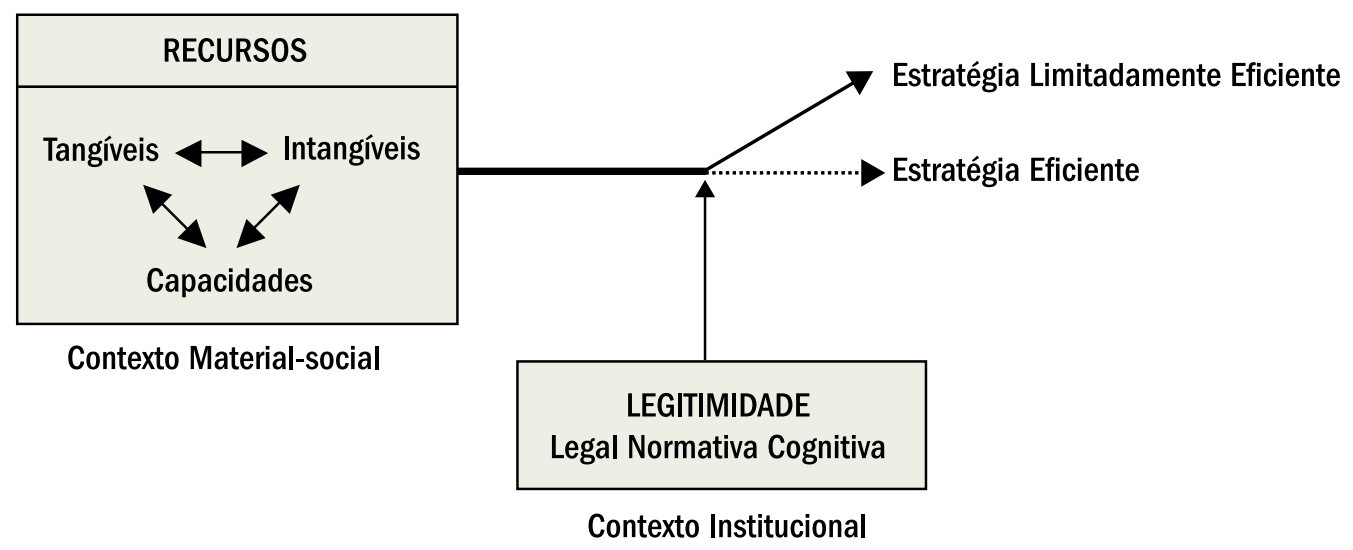


O que a Figura 2 retrata é, primeiramente, que recursos são valiosos apenas quando são interpretados como sendo valiosos. Essa ênfase em interpretação emerge da própria NTI, quando aplicada ao entendimento de questões pertinentes à estratégia e aos recursos organizacionais (De GREGORI, 1987; THORNTON, JONES e KURY, 2005). Igualmente, qualquer padrão institucional legal, normativo ou cultural-cognitivo, só é fonte de legitimidade quando interpretado como tal. Por outro lado, a posse de recursos por parte de agentes pessoais ou organizacionais e a existência de padrões institucionais a que os agentes já atendem também podem gerar tendências ou predominâncias de interpretação. É o que está representado pelas setas A e B, na Figura 2: há a tendência para se interpretar como valiosos recursos e competências que já estão em posse dos indivíduos e organizações e como legítimos padrões institucionais que já são atendidos.

Quanto à relação representada pela seta C, ela indica que parece plausível admitir que recursos buscam legitimidade, isto é, que a posse de recursos impulsiona esforços para configuração de ambiente institucional favorável àqueles recursos de que já se dispõe e, ao mesmo tempo, implica dizer que a legitimidade tende a facilitar o acesso a mais recursos. É por meio dessa tríade sincrônica que se explica, finalmente, a ação estratégica eficiente (seta D) que, nesses termos, incorpora tanto elementos materiais e sociais (recursos) quanto institucionais (legitimidade), não de modo separado, mas entendendo-os como codependentes entre si e em relação dinâmica. Dada essa mutualidade constitutiva, rompe-se o pressuposto que explica o papel das referências institucionais - da legitimidade, portanto - como sendo apenas negativo, limitante da eficiência da ação, trazendo as noções de legitimidade, recursos e da própria eficiência estratégica para dentro do escopo mais recente da NTI em organizações, no que tange ao entendimento do papel constitutivo das instituições (SCOTT, 2001; THORNTON, JONES e KURY, 2005).

Assim, não somente o valor de um recurso, como também o próprio fato de algo ser considerado como recurso decorrem das dimensões cognitiva e institucional. Essas dimensões, por sua vez, são entendidas não apenas como filtro da realidade objetiva ou interveniente no processo de ação estratégica, mas também como o seu próprio fundamento. O resultado desse processo seria, então, uma ação estratégica que não é estritamente racional nem apenas limitadamente racional. Nos termos do segundo conjunto de relações (Figura 2), a ação estratégica é entendida como resultante de uma eficiência possível, pois a necessária legitimidade dos recursos não apenas limita as escolhas que se podem fazer. A legitimidade está na base dessas mesmas escolhas, de modo que, se referências institucionais permitem apenas escolhas

Figura 2 - Recursos, legitimidade e eficiência possível

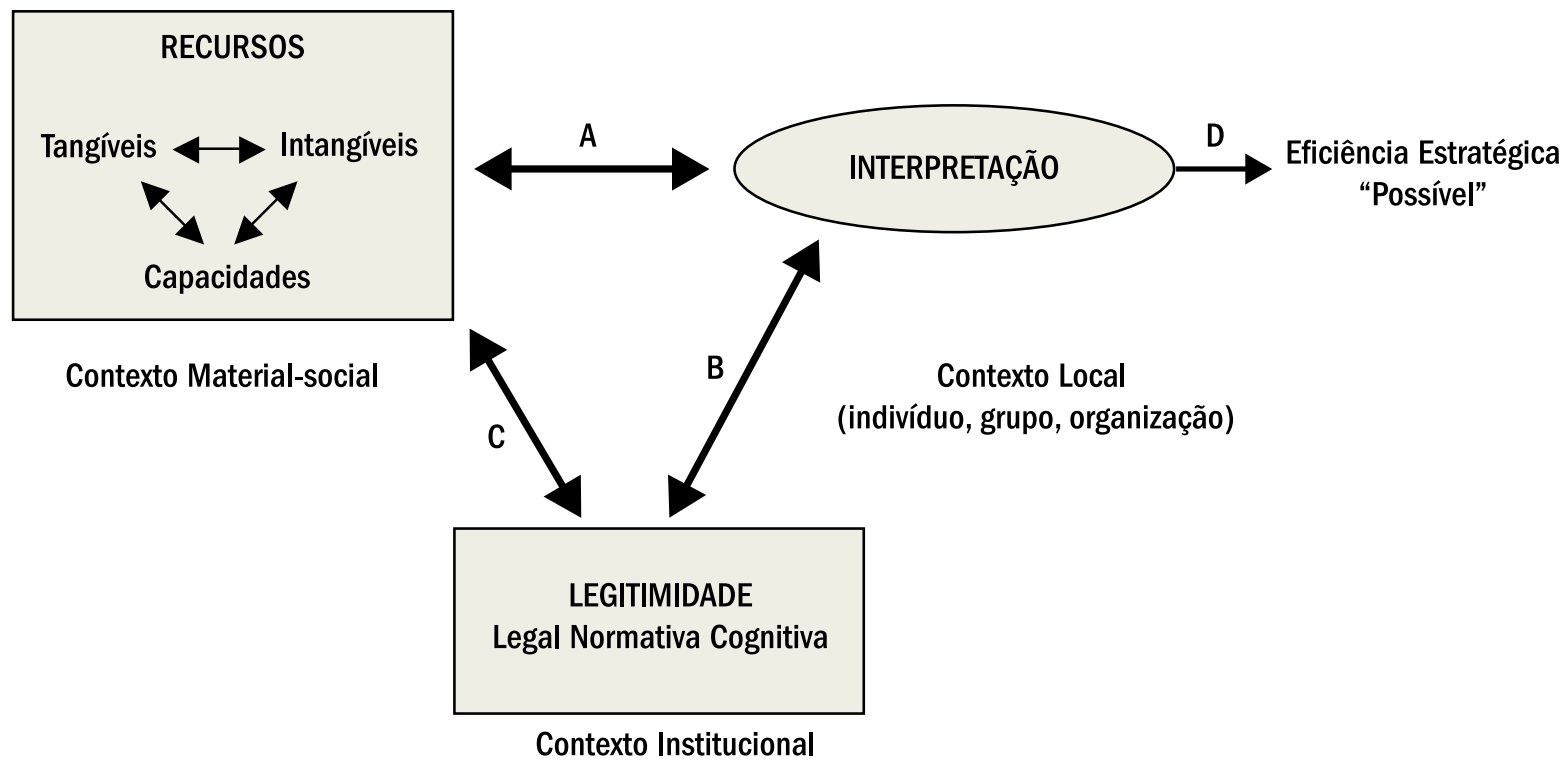


limitadas, sem elas não se teria escolha alguma, pelo fato de que, sem legitimidade, recursos e competências não podem ser julgados quanto a seu valor e não podem ser estrategicamente selecionados, acumulados e dispostos. Se com referências institucionais a eficiência seria limitada, sem elas não haveria eficiência alguma, porque o atributo eficiência é uma definição social; portanto, derivado e dependente do contexto institucional específico em que uma ação eficiente é desempenhada.

\section{CONSIDERAÇÕES FINAIS}

Na versão aqui preliminarmente proposta, torna-se possível entender a construção de vantagem competitiva para além do âmbito do planejamento interno das organizações ou mero monitoramento do ambiente. A partir das noções desenvolvidas dentro do escopo teórico da VBR, a eficiência estratégica é produto de dinâmica racional, ainda que limitada, da firma. Ao propor expansão dessa idéia, no que chamamos aqui de Visão Baseada em Recursos Legítimos, buscamos incluir a dimensão ambiental na discussão da eficiência estratégica, tomando como padrão a NTI, isto é, assumindo não apenas o conjunto objetivo de fatores externos, como também as forças e as orientações intersubjetivamente produzidas.

O ambiente organizacional, na NTI, não se limita a padrões objetivos e técnicos. Ele possui uma faceta referente a orientações de natureza legal, normativa e cognitiva. Esse outro lado do ambiente compreende um conjunto de estruturas ou traços virtuais de memória (GIDDENS, 2003) que se manifestam no momento em que se torna necessário decidir e agir. A sua incorporação na dinâmica explicativa da eficiência estratégica e, especificamente, na explicação dada pela VBR para tal eficiência rompe, é certo, com premissas caras à visão econômica das empresas, mas pode ser importante para revelar a natureza dupla dos recursos organizacionais. Recursos aqui são entendidos como tendo uma face externa e objetiva e também uma face intersubjetiva e simbólica, decorrente do fato de que recursos e competências são também parte da realidade socialmente construída. Isso já é tendência na própria VBR, mas nos parece não ter ainda afetado suficientemente a própria noção de recursos, que é central para o conjunto de suas teorias.

Essa versão aqui proposta também coloca em dúvida o ideal racional da atuação do estrategista e do seu poder de planejamento. Nos termos da discussão aqui conduzida, a vantagem competitiva é menos produto de ações intencionais e mais fruto de lógica sistêmica parcialmente fora do escopo das possibilidades de planejamento consciente e intencional. Isso está mais próximo da lógica evolucionária, entendendo a obtenção de vantagem competitiva como decorrência principalmente de forças sistêmicas e ambientais que se encontram aleatoriamente, com concurso apenas parcial da intencionalidade, e para a qual o estrategista atua, no máximo, como um catalisador de tendências. Nessa, como em outras versões do evolucionismo social (BARNEY, 2001a), a escolha deliberada é importante na medida em que gera variações necessárias à evolução, mas não se pode incluí-la como a fonte primeira e exclusiva daquele processo. Da mesma forma, a vantagem e até a desvantagem podem ser vistas, mediante aquele modelo, como sempre provisórias, mas não totalmente fluidas, uma vez que são em essência dependentes da interpretação predominante.

O tratamento apenas introdutório dado a essas questões, neste texto, sugere a necessidade de aprimoramento conceitual e exploração empírica das idéias aqui delineadas. Acreditamos, contudo, no seu valor para indicar caminhos pelos quais possa ocorrer a incorporação de noções institucionalistas no entendimento da estratégia pela via da Visão Baseada em Recursos. Espera-se que a perda do potencial prescritivo, decorrente da versão aqui proposta, seja compensada pelo ganho do potencial analítico que dela parece advir e que certamente pode ser aumentado na medida em que ela se torne alvo de crítica e aperfeiçoamento.

Quanto ao nosso substrato teórico, discutimos apenas preliminarmente como recursos podem ser entendidos enquanto "virtuais", noção proposta por Giddens, mas criticada desde então. No atual estágio, a VBR parece flertar com essa proposta (HELFAT e PETERAF, 2003). Acreditamos que é nela que se poderá, em primeira mão, dar passo significativo para a operacionalização daquela definição, e a NTI pode oferecer contribuição fundamental se trazida para o escopo teórico da VBR. Outro passo necessário é romper barreiras da economia das organizações para a aceitação de premissas sociológicas relativas à origem social das ações e das instituições. Isso já vem ocorrendo via sociologia econômica, mas há ainda resistências derivadas das diferentes tradições de pensamento que marcam ambos os corpos teóricos. Acreditamos que a discussão da natureza recursiva da ação, em relação a estruturas sociais, seja passo importante para superar o que Hall e Taylor (2003) chamaram de "imagem relativamente simplista das motivações humanas", quando essas são tomadas apenas enquanto auto-interessadas e estrategicamente conduzidas. Discutir a noção de limites da racionalidade é, para nós, o ponto-chave para que se 
compreenda o papel do entorno social na racionalidade, e isso só se poderá fazer com vantagens a partir de uma volta às noções coletivistas do processo de emergência das estruturas sociais como produtos da própria sociedade, ainda que com o concurso inescapável de atores sociais que agem racionalmente.

\section{REFERÊNCIAS}

ACEDO, F; BARROSO, C; GALAN, J. The resource-based theory: dissemination and main trends. Strategic Management Journal, v. 27, n. 7, p. 621-636, 2006.

BARNEY, J. Firm resources and sustained competitive advantage. Journal of Management, v.17, n. 1, p. 99-120, 1991.

BARNEY, J. Gaining and sustaining competitive advantage. Reading: Adisson Wesley, 1997.

BARNEY, J. Is the resource-based "view" a useful perspective for strategic management research? Yes. Academy of Management Review, v. 26, n. 1, p. $41-56,2001 \mathrm{a}$

BARNEY, J. Resource-based theories of competitive advantage: a ten-year retrospective on the resource-based view. Journal of Management, v. 27, n. 6 , p. $643-650,2001 \mathrm{~b}$.

BARNEY, J; HESTERLY, W. Organizational economics: understanding the relationship between organizations and economic analysis. In: CLEGG, S; HARDY, C; NORD, W. (Ed) Handbook of organization studies. London: Sage, 1996. p. 115-147.

BIDWELL, C. Varieties of institutional theory: traditions and prospects for educational research. In: MEYER, H.; ROWAN, B. (Ed) The new institutionalism in education. Albany: State University of New York Press, 2006. p. 33-50.

BOUDON, R. Beyond rational choice theory. Annual Review of Sociology, v. 29, n. 1, p. 1-21, 2003

COLLIS, D; MONTGOMERY, C. Competing on resources: strategy in the 1990s. Harvard Business Review, v. 74, n. 4, p. 118-128, 1995.

De GREGORI, T. Resources are not; they become: an institutional theory. Journal of Economic Issue, v. 21, n. 3, p. 1241-1263, 1987.

DiMAGGIO, P; POWELL, W. The iron cage revisited: institutional isomorphism and collective rationality in organizational fields. American Sociological Review, v. 48, n. 8, p. 147-160, 1983.

DiMAGGIO, P; POWELL, W. Introduction. In: POWELL, W; DiMAGGIO, P. (Ed) The new institutionalism in organizational analysis. Chicago: University of Chicago Press, 1991. p. 1-40.
FOSS, N. The classical theory of production and the capabilities view of the firm. Journal of Economic Studies, v. 24, n. 5, p. 307-323, 1997.

FOSS, K; FOSS, N. Resources and transaction costs: how property rights economics furthers the resource-based view. Strategic Management Journal, v. 26, n. 6, p. 541-553, 2005.

GIDDENS, A. A constituição da sociedade. São Paulo: Martins Fontes, 2003

GIDDENS, A. Central problems in social theory. London: Macmillan Press 1979

GRANT, R. The resource-based theory of competitive advantage: implications for strategy for strategy formulation. California Management Review, v. 33, n. 3, p. 114-135, 1991.

HALL, P; TAYLOR, R. As três versões do neo-institucionalismo. Lua Nova, v. 58, n. 1, p. 193-223, 2003.

HELFAT, C; PETERAF, M. The dynamic resource-based view: capability lifecycles. Strategic Management Journal, v. 24, n. 10, p. 997-1010, 2003.

HININGS, C; GREENWOOD, R. The dynamics of strategic change. New York: Basil Blackwell, 1988.

HOLM, P. The dynamics of institutionalization transformation processes in Norwegian fisheries. Administrative Science Quarterly, v. 40, n. 1, p. 398-422, 1995.

MACHADO-DA-SILVA, C; FONSECA, V. Competitividade organizacional: conciliando padrões concorrenciais e padrões institucionais. In: VIEIRA, M; OliVEIRA, L. (Org) Administração contemporânea. São Paulo: Atlas, 1999. p. 27-39

MEYER, $\mathrm{H}$. The rise and decline of the common school as an institution taking 'myth and ceremony' seriously. In: MEYER, H.; ROWAN, B. (Ed) The new institutionalism in education. Albany: State University of New York Press, 2006. p. 51-66.

MUTCH, A. Reflexivity and the institutional entrepreneur: a historical exploration. Organization Studies, v. 28, n. 7, p. 1123-1140, 2007.

OLIVER, C. Sustainable competitive advantage: combining institucional and resource-based views. Strategic Management Journal, v. 18, n. 9, p. $697-713,1997$

OLIVER, C. Strategic responses to institutional processes. Academy of Management Review, v. 16, n. 1, p. 145-179, 1991.

PENROSE, E. The theory of the growth of the firm. New York: John Wiley, 1959

PETERAF, M. The cornerstones of competitive advantage: a resource-based view. StrategicManagement Journal, v. 14, n. 3, p. 179-191, 1993 
QUEIROZ, M; VASCONCELOS, F; GOLDSZMIDT, R. Economic rents and legitimacy: incorporating elements of organizational analysis institutional theory to the field of business strategy. Brazilian Administration Review, v. 4, n. 1, p. 51-65, 2007.

ROBERTS, P; GREENWOOD, R. Integrating transaction cost and institutional theories: toward a constrained-efficiency framework for understanding organizational design adoption. Academy of Management Review, v. 22, n. 2, p. 346-373, 1997.

RUBIN, P. The expansion of the firms. Journal of Policital Economy, v. 81, p. $936-949,1973$

RUGMAN, A; VERBEKE, A. Edith Penrose's contribution to the resourcebased view of strategic management. Strategic Management Journal, v. 23, n. 8, p. 769-780, 2002.

SCOTT, W. R. Institutions and organizations. 2. ed. London: SAGE, 2001.

SPANOS, Y; LIOUKAS, S. An examination into the causal logic of rent generation: contrasting Porter's competitive strategy framework and the resource-based perspective. Strategic Management Journal, v. 22, n. 10, p. 907-934, 2001.

SUCHMAN, M. Managing legitimacy: strategic and institutional approaches. Academy of Management Review, v. 20, n. 3, p. 571-610, 1995.
TEECE, D; PISANO, G. The dynamic capabilities of firms: an introduction. Industrial and Corporate Change, v. 3, n. 3, p. 537-556, 1994.

TOLBERT, P; ZUCKER, L. The institutionalization of institutional theory In: CLEGG, S; HARDY, C; NORD, W. (Ed) Handbook of organization studies. London: Sage, 1996. p. 175-190.

THORNTON, P. The rise of the corporation in a craft industry: conflict and conformity in institutional logics. Academy of Management Journal, v. 45, n. 1, p. 81-101, 2002.

THORNTON, P; JONES, C; KURY, K. Institutional logics and institutional change in organizations: transformation in Accounting, Architecture, and Publishing. In: THORNTON, P. (Org) Transformation in cultural industries. Amsterdam: Elsevier, 2005. p. 125-170.

WEBER, K; GLYNN, M. Making sense with institutions: context, thought and action in Karl Weick's theory. Organization Studies, v. 27, n. 11, p. 1639-1660, 2006.

WERNERFELT, B. A resource-based view of the firm, Strategic Management Journal, v. 5, p. 171-180, 1984.

WHITTINGTON, R. Putting Giddens into action: social systems and managerial agency. Journal of Management, v. 29, n. 6, p. 693-712, 1992. 